\title{
Influence of a Femtosecond Laser Surface Modification on the Fatigue Behavior of Ti-6Al- 4V ELI Alloy
}

\author{
Alan dos Santos ${ }^{a}$, Leonardo Contri Campanelli *®י, Paulo Sergio Carvalho Pereira da Silva ${ }^{a}$, \\ Rui Vilar ${ }^{b}$, Maria Amélia Martins de Almeida ${ }^{b}$, Alexei Kuznetsov ${ }^{c}$, Carlos Alberto Achete, \\ Claudemiro Bolfarini ${ }^{a}$
}

\author{
${ }^{a}$ Departamento de Engenharia de Materiais, Universidade Federal de São Carlos, Rod. Washington \\ Luiz km. 235, CEP: 13565-905, São Carlos, SP, Brasil \\ ${ }^{b}$ Departamento de Engenharia de Química, Instituto Superior Técnico, Av. Rovisco Pais, 1049-001, \\ Lisboa, Portugal

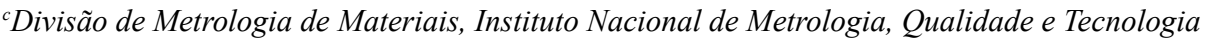 \\ (INMETRO), Av. Nossa Senhora das Graças 50, CEP 25250-020, Duque de Caxias, RJ, Brasil
}

Received: February 08, 2019; Revised: April 20, 2019; Accepted: May 12, 2019

\begin{abstract}
The objective of this investigation was to evaluate the influence of surface modification by femtosecond laser (with average fluence of $0.6 \mathrm{~J} / \mathrm{cm}^{2}$ and scanning speed of $0.1 \mathrm{~mm} / \mathrm{s}$ ) on the fatigue resistance of Ti-6Al-4V ELI alloy. A significant reduction in the fatigue strength of the material modified by laser was observed. Residual tensile stresses generated during surface modification were negligible, presenting lower values than those found on the unmodified surface. Based on a recently developed and published prediction model, the reduction of the fatigue strength was ascribed to the surface roughness created during the laser treatment of the alloy. An evidence was that the fatigue crack nucleation occurred in the modified region, rather than at the edge of the rectangular specimens as in the untreated condition.
\end{abstract}

Keywords: Ti-6Al-4V ELI, surface modification, laser, femtosecond, fatigue.

\section{Introduction}

Titanium and its alloys, originally developed for aeronautical applications, have been increasingly used in applications as biomaterials because of their excellent mechanical strength, low modulus of elasticity, low density, high corrosion resistance, and the best biocompatibility among the metallic biomaterials. There are two main methods for fixation of the orthopedic implant to the bone: use of a cement with PMMA (polymethylmethacrylate) or modified implants surfaces (bio-passive and bio-active) to promote osseointegration ${ }^{1}$. The first method is commonly used in older patients with impaired ability to regenerate bone. Polished prostheses are used (usually stainless steel) and the result is an excellent primary fixation, i.e., no biological interaction between prosthesis/bone ${ }^{2}$.

The second method is based on the improvement of the long-term success of the implant/bone interface, that depends on the capacity to stimulate the osseointegration phenomenon, by altering the physical and/or chemical properties of the surface. The osseointegration is influenced by the following surface properties: morphology, topography, roughness, chemical composition, surface energy and wettability. Interactions between two or more properties are likely to happen and therefore to affect the implant stability, which plays a critical role for a successful osseointegration ${ }^{3}$. Several techniques

*e-mail: leoccampa@hotmail.com are used for this purpose and there are clinical advantages for their use as compared to the first method described ${ }^{4,5}$.

From the mechanical point of view, however, surfaces modified by conventional methods for improvement of osseointegration, such as plasma electrolytic oxidation ${ }^{6}$, thermal oxidation and corundum grit blasting ${ }^{7}$, can drastically reduce the fatigue resistance of prostheses, since, as it is well known, the fatigue behavior is strongly dependent on surface and near surface characteristics. The reason is that the fatigue property is typically affected by the increase in roughness, formation of notches or pores and/or emergence of residual stresses ${ }^{8}$. Thus, the combination and balance between the improvement of osseointegration and mechanical behavior is a challenge for the development of orthopedic implants 9.

Advances in the techniques of surface modification and characterization, based on nanotechnology and its applications, indicate that modified surfaces at the nano-meter scale can promote higher osseointegration than surfaces modified by current techniques ${ }^{10}$. The laser surface modification shows promise to improve the osseointegration since it permits precise control of parameters, geometrically defined surface features with controlled dimensions, and induces reduced mechanical and thermal damage. The femtosecond laser is particularly interesting since it uses pulses with duration of femtoseconds, which allows the creation of nano-sized features on a surface and reduces the occurrence of thermal damage ${ }^{11-13}$. 
The objective of this investigation was to evaluate the influence of surface modification by femtosecond laser on the fatigue resistance of Ti-6Al-4V ELI alloy specimens, considering both the surface topography and changes induced by the heat input.

\section{Materials and Methods}

Dimensions of the fatigue test samples are shown in Figure 1 (according to ASTM F1160) were machined from $3 \mathrm{~mm}$ thick Ti-6Al-4V ELI (ASMT F136) plates maintaining the surface finish and microstructure of the initial rolled plates. Rectangular areas of $10 \times 4 \mathrm{~mm}^{2}$ in the middle of the reduced section were modified by laser treatment. For the surface modification, a pulsed Yb:KYW laser was employed (Amplitude Systemes s-Pulse HP), with pulse duration lower than $500 \mathrm{fs}$ and wavelength of $1030 \mathrm{~nm}$. The pulse repetition rate was kept at $50 \mathrm{~Hz}$ and the scanning speed was approximately $100 \mu \mathrm{m} / \mathrm{s}$. The average power before and after the mirror were respectively $0.800 \mathrm{~W}$ and 0.770 $\mathrm{W}$, with an average fluence of $0.6 \mathrm{~J} / \mathrm{cm}^{2}$.

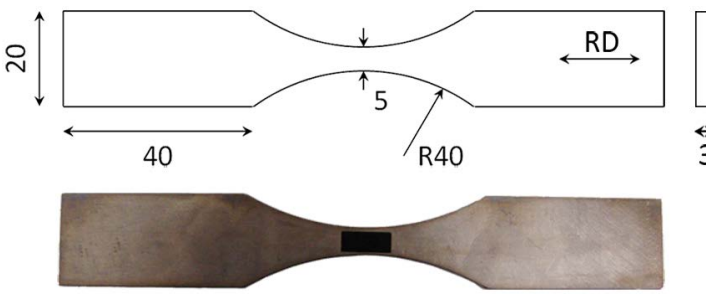

Figure 1. Illustration of the test specimen (dimensions in $\mathrm{mm}$ ) and photograph of a treated sample. RD refers to the rolling direction.

The laser beam was focused by $100 \mathrm{~mm}$ focal length lens on a spot perpendicular to and at the specimen surface, with a diameter of $338 \pm 10 \mu \mathrm{m}$. The laser treatment was performed under standard air atmosphere by moving the specimens under the stationary laser beam with a constant scanning speed through a computer-controlled XYZ stage. To achieve complete surface coverage, consecutive laser tracks were partially overlapped by a lateral displacement of about $30 \%$ of the laser track width. All these parameters were chosen according to previous experience at Instituto Superior Técnico to produce a nanoscale modification consisting of nanoscale laser-induced periodic surface structures (LIPSS) overlapped onto microcolumns.

The roughness evaluation was carried out using both a contact perfilometer Mitutoyo SJ-201P, with two measurements in each of four samples, and a confocal laser scanning microscope (CLSM) Olympus Lext OLS 400. CLSM measurement was performed in a single specimen, chosen at random. The assessment of surface topography, the metallographic analysis of cross-sectional area and the fatigue fracture surface characterization were performed using a scanning electron microscope (SEM) FEI Quanta 400 FEG. With the same microscope, energy dispersive spectroscopy (EDS) by an Oxford INCA Energy 250 detector was employed to evaluate the oxygen content near the surface of the modified region.

Bending type fatigue tests were conducted in a Brasvalvulas BME 0540150 / AT MNB servo-hydraulic equipment, using the device illustrated in Figure 2 and a load applicator consisting of a roller straightened supported by self-aligning bearings. The frequency of the load application was $5 \mathrm{~Hz}$ and the ratio between the minimum and maximum load was 0.1 . Two fatigue test programs involved seven non-treated (reference) and ten laser-modified samples, nearly uniformly replicated at four stress levels, resulting in replications of $43 \%$ and $60 \%$ for reference and modified samples, respectively. These levels of replication are suitable for research and development testing according to the ASTM E739.

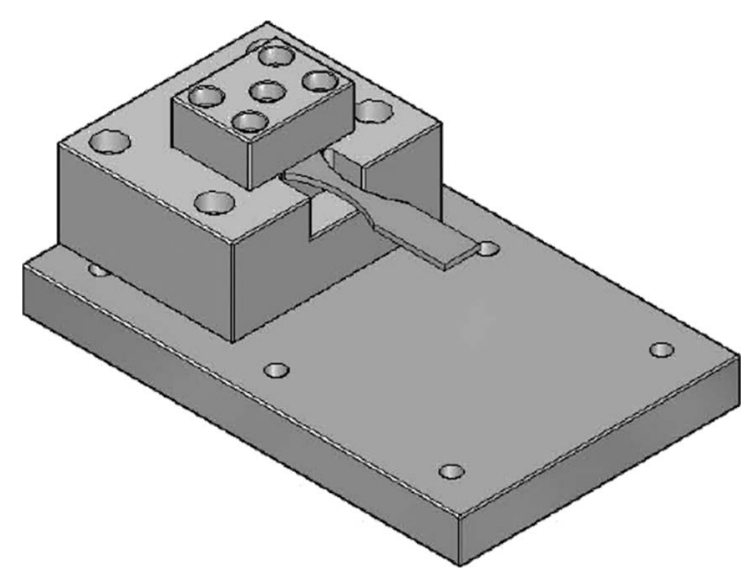

Figure 2. Device used in the bending fatigue tests.

The measurements of the in-plane surface stress component along the larger side of the selected rectangular areas of the laser modified and reference samples were carried out on a Bruker's D8-Discover X-ray diffractometer in $\Psi$ experimental geometry (side inclination) ${ }^{14}$ with the use of Co $\mathrm{K}_{\alpha}$ radiation, measuring the (114) diffraction line of $\alpha$-Ti phase of samples. These radiation conditions provide nearly backscattering geometry for (114) peak's measurements $(2 \Theta$ peak's position is about 158?). A collimated by a $1 \mathrm{~mm}$ circular slit X-ray beam was centered in the middle of the rectangular area of the tested samples. Each measurement consisted of a collection of (114) diffraction peaks corresponding to positive and negative values of $\psi$ in the range from -60 ? to 60 ? with the $\Delta \psi$ step of $5 ?$. The determination of the (411) peak positions employed a pseudo-Voigt function fit of the measured diffraction peaks corrected for background, absorption, Polarization-Lorenz factor, $\mathrm{K}_{\alpha 2}$ contribution as implemented in the Stress V1.1 software from Bruker-AXS. 


\section{Results and Discussion}

The samples were subjected to femtosecond laser nonstationary irradiation, with an energetic fluence of $0.6 \mathrm{~J} / \mathrm{cm} 2$, which did suffice for the formation of micro-columns, as shown in Figure 3. It is noted in Figure 4 a bimodal surface of nanoscale laser-induced periodic surface structures (LIPSS) covering all these micro-columns. The spatial periodicity of the LIPSS was approximately $700 \mathrm{~nm}$, i.e., substantially lower than the equipment wavelength of $1030 \mathrm{~nm}$. Typical of stationary irradiation, the LIPSS structure is usually formed with fluences near the melting threshold, more specifically when fluence is lower than the threshold fluence for microcolumns formation and larger than the melting threshold fluence. This difference could be explained by the formation of nanostructures during the first pulses of laser, which increase the real part of refractive index of the material ${ }^{11}$.

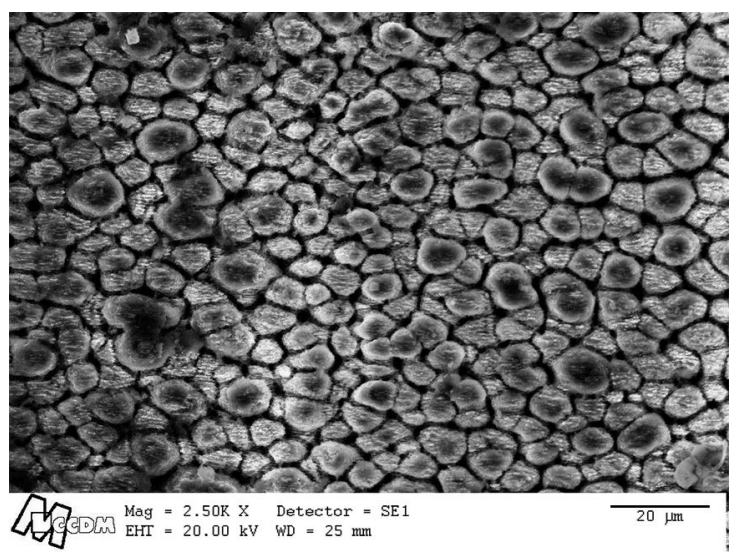

Figure 3. SEM micrograph of the overall appearance of microcolumns formed.

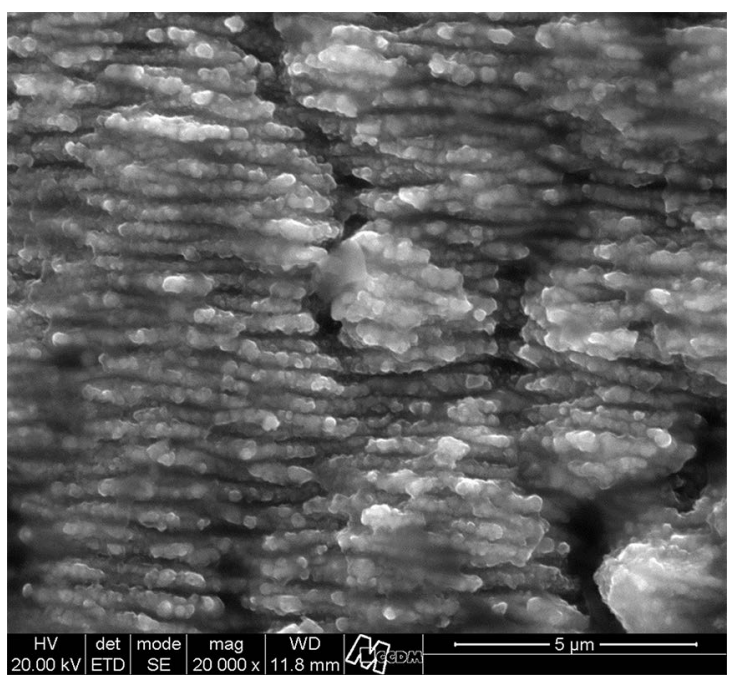

Figure 4. SEM micrograph of LIPSS covering all micro-columns.
During non-stationary irradiation, each point of the specimen is subjected to different energetic fluences, because the energy profile in cross section of the laser beam follows a Gaussian distribution and depends on, among other factors, the beam diameter, the average value of fluency and the scanning speed. Thus, the LIPSS are developed immediately after the formation of micro-columns, when the material is exposed to the lower energy intensity of the beam ${ }^{11,12}$. Due to the processing in air, modification by laser also induced the formation of a surface oxide, as shown in Figure 5. Depending on the parameters used in the equipment, different oxides such as rutile, anatase and even alumina can be expected ${ }^{15,16}$. It is known that the formation of these oxides provides higher corrosion resistance and enhances the wettability of the surface, an essential property in the process of osseointegration ${ }^{16}$. The observation by SEM of cross sections of the specimen showed no severe microstructural changes on the alloy close to the modified surface.

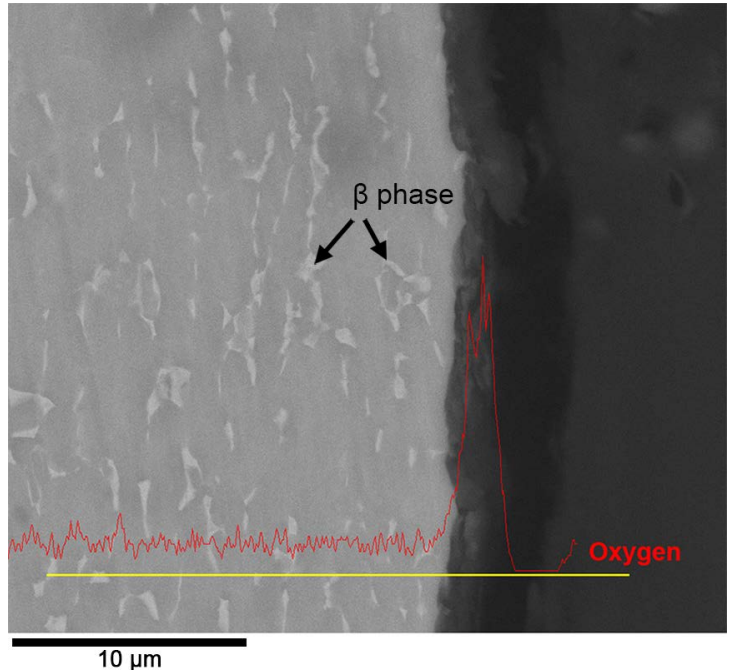

Figure 5. SEM micrograph of the cross-section showing the surface oxide layer.

This is an important issue to be addressed, because, from the decades of 1960-1970 on, it is recognized the strong influence of $\alpha$-case formation on reducing the fatigue strength of Ti alloys. When heated in solid state, the surface of Ti-6Al-4V reacts with oxygen, which is an $\alpha$-stabilizer element, resulting in a structure predominantly of $\alpha$ phase. Oxygen is soluble in Ti up to $3.5 \%$ wt. at $673 \mathrm{~K}$ and has a significant hardening effect ${ }^{17}$. The oxygen-enriched surface forms an $\alpha$-case and allows oxygen to diffuse through the underlying matrix of the base alloy. Depending on the time and temperature, this diffusion layer can reach $\sim 200 \mu \mathrm{m}$ after isothermal heat treatment in air at $700^{\circ} \mathrm{C}$ for 500 hours ${ }^{18}$. In investment cast parts, this layer can be even thicker 
and reach $500 \mu \mathrm{m}^{19}$. Such $\alpha$-case is detrimental to Ti-6Al$4 \mathrm{~V}$ due to its brittle nature, and can result in early surface cracks under cyclic tension ${ }^{20}$. Therefore, in order to allow a reliable interpretation of the fatigue results, it is of utmost importance to identify the presence or absence of $\alpha$-case.

By a careful observation of Figure 5, it is observed that no microstructural alterations occurred since the $\beta$-phase distribution was unchanged through the sample thickness. In addition, the EDS scan line on the cross-section showed that the oxygen content remained constant and only changed over the oxide layer. This endorses that no $\alpha$-case was formed, regardless of the presence of the oxide layer, and that any change in the fatigue strength must not be ascribed to it. The formation of $\alpha$-case is not expected due to the very fast cooling rates prevailing in the femtosecond laser processing (higher than $10^{6} \mathrm{~K} / \mathrm{s}$ ) ${ }^{16}$. Although oxygen is available, the diffusion time is very short, in the range of $10^{-3} \mathrm{~s}$. The thickness of the $\alpha$-case can be estimated by the following relationship ${ }^{21}$ :

$$
\delta_{\alpha}=(D . t)^{1 / 2}
$$

where $D$ is the diffusion coefficient for oxygen in the $\beta$ phase $\left(7,98 \times 10^{-12} \mathrm{~m}^{2} \mathrm{~s}^{-1}\right)$ and $t$ is the time for diffusion. Considering $\mathrm{t}=10^{-3} \mathrm{~s}$, which is a rough estimation for the cooling down from the melting temperature $\left(\sim 1730^{\circ} \mathrm{C}\right.$ to $\left.\sim 500^{\circ} \mathrm{C}\right)$, the latter meaning the temperature below which the diffusion mechanism is negligible, the thickness of the $\alpha$-case can be calculated as around $9 \mathrm{~nm}$. In spite of the rough calculation of the possible $\alpha$-case thickness, its size is indeed in the nanometer scale, thus justifying the impossibility of observing it with the available techniques. In this size scale, there is no related effect on the fatigue properties so far, and this influence can be safely excluded in this work to justify the fatigue performance.

The fatigue tests showed that, despite of the bending test type and of the device with self-compensating bearings in order to ensure alignment, all reference specimens showed fatigue crack nucleation at the edge. River patterns emanating from the point with an arrow, as observed in Figure 6, indicate that this is the probable nucleation site. On the other hand, all specimens with surface modified by femtosecond laser showed nucleation of fatigue crack in the middle third of the width, or approximately in the center of the modified surface, as shown in Figure 7. The accurate nucleation site is hardly distinguished in this case: although faintly seen, the river patterns denote the crack initiation in the aforementioned position.

Figure 8 shows the S-N curves obtained for the two conditions evaluated. The untreated material presented an approximated fatigue strenght of $725 \mathrm{MPa}$, whereas the lasertreated material presented a fatigue strenght of around 650 $\mathrm{MPa}$. The dotted lines comprise the $95 \%$ confidence band

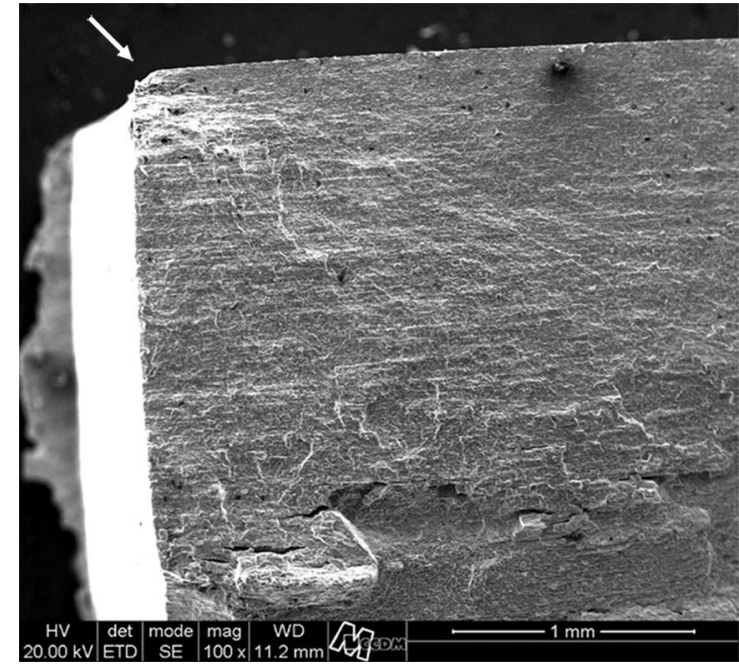

Figure 6. SEM micrograph of the fatigue initiation region of a reference sample. The arrow points at the crack initiation at the edge.

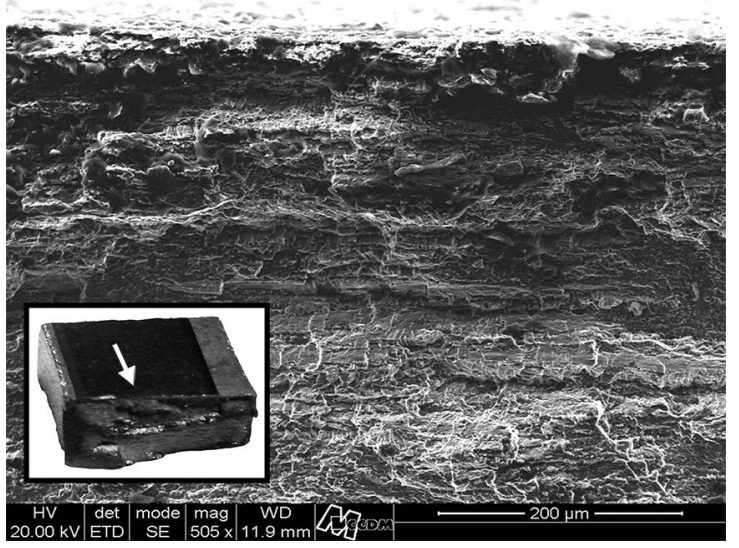

Figure 7. SEM micrograph of the fatigue initiation region of a lasertreated sample. The inset image is a macrograph of the fractured sample, and the arrow indicates the probable initiation site.

computed in accordance with the ASTM E739 standard. Since there is no intersection between the bands, it is possible to conclude that the difference in the fatigue behavior of both conditions is statistically significant. There is therefore an irrefutable deleterious influence of the femtosecond laser on the fatigue response of the material.

Due to the well known influence of surface residual stresses on the fatigue limit, measurements were conducted to determine their value on the surface of modified and reference samples. Figure 9 shows the curves obtained and the results at the geometric center of the samples. The residual stresses at the surface are very small and, moreover, with smaller values of the modified samples (around $20 \mathrm{MPa}$ against $46 \mathrm{MPa}$ of the unmodified material). Hence, these results cannot explain the smaller values for the fatigue strength of the laser modified samples. 


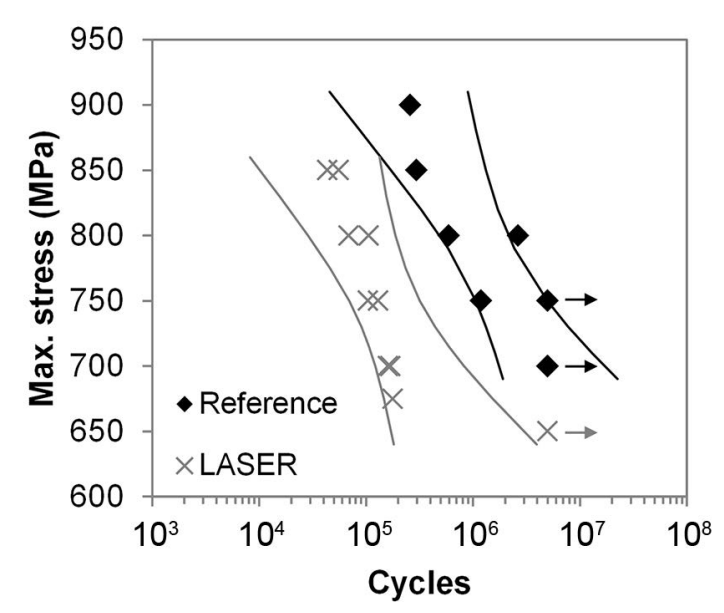

Figure 8. S-N curves for the untreated (reference) and laser-treated conditions.

The results of surface roughness of modified and reference samples are presented in Table 1. There is a difference in the results obtained with the techniques, although the standard deviation values indicate that such difference is not significant.
Table 1. Results of Rz roughness measurements (in $\mu \mathrm{m}$ ) for both surfaces.

\begin{tabular}{ccc}
\hline Equipment & Reference & Laser \\
\hline Perfilometer & $3.55 \pm 0.71$ & $7.55 \pm 0.94$ \\
CLSM & $2.45 \pm 0.71$ & $6.37 \pm 0.63$ \\
\hline
\end{tabular}

It is well known, that the effect of roughness on the fatigue strength may be evaluated by the fatigue notch factor $\mathrm{K}_{\mathrm{f}}$. This factor is essentially different from the monotonic concentration factor $\mathrm{K}_{t}$, since it depends on the material, and, below a certain tip radius of the notch, its effect decreases and becomes negligible. This factor may be calculated from a constant, typical of a certain material, which is determined experimentally from fatigue results of notched specimens, with known geometrical notches. This calculation for Ti6Al-4V ELI was recently published by da Silva et al. ${ }^{22}$, and thus a prediction method was established.

The differences of surface roughness obtained in the present work (Table 1) were analysed through this predition method, and the results are summarized in Table 2. For each roughness value, $\mathrm{K}_{\mathrm{f}}$ was obtained in the aforementioned reference ${ }^{22}$. The value of the fatigue limit expected with $K_{f}$
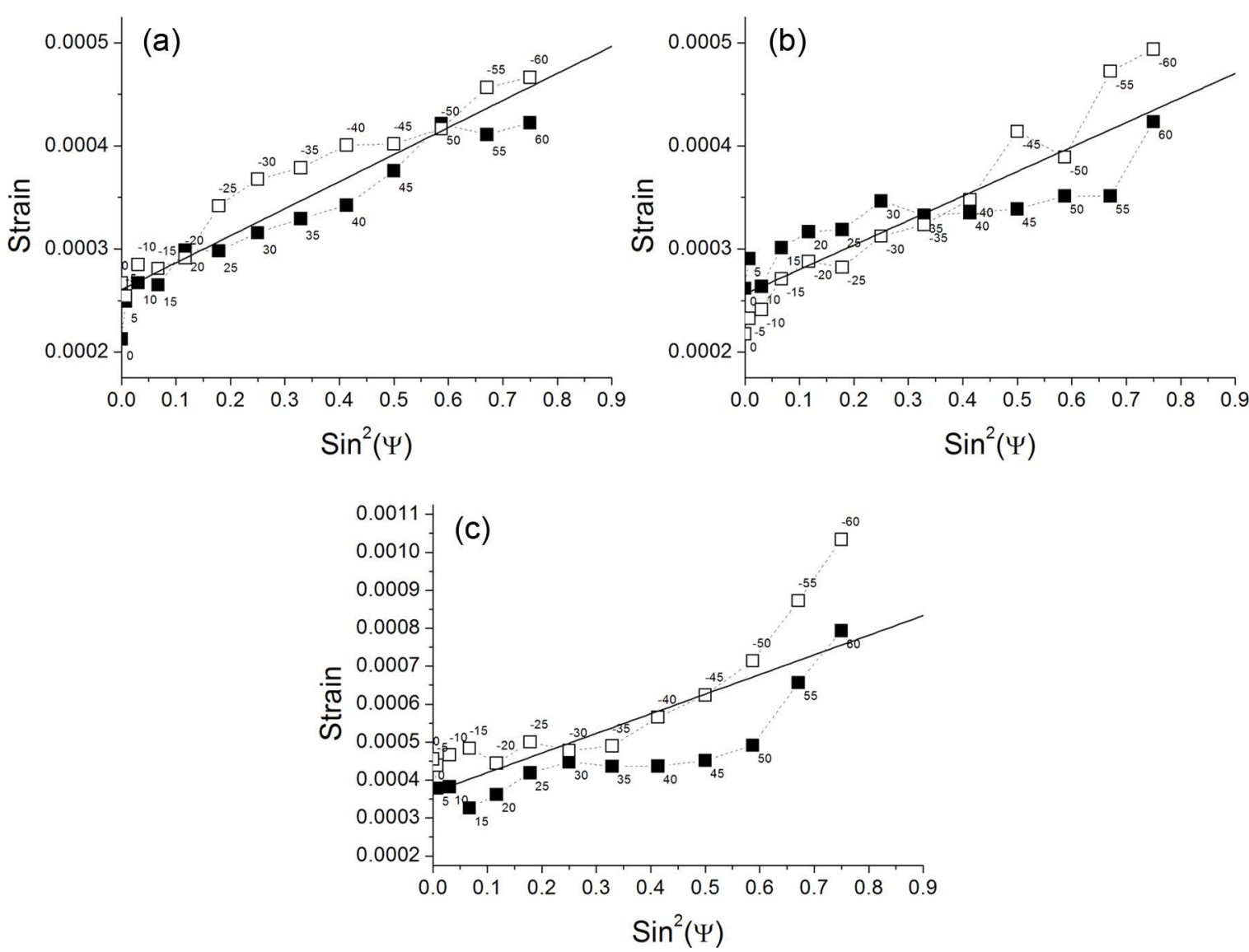

Figure 9. Curves of strain in function of $\sin ^{2}(\Psi)$ : (a) surface 1 of modified sample (residual stress of $23 \mathrm{MPa}$ ), (b) surface 2 of modified sample (residual stress of $21 \mathrm{MPa}$ ) and (c) surface of reference sample (residual stress of $46 \mathrm{MPa}$ ). White and black squares represent the $\Psi$ angles used for the measurements (black are positive angles and white are negative angles). 
$=1$ (smooth surface) was taken as $850 \mathrm{MPa}$, the best value according to several previous measurements in cylindrical specimens of Ti-6Al-4V ELI alloy of the same production lot ${ }^{8,23}$. For the laser-treated samples, the expected and measured fatigue limits are noticiably in good agreement, with small errors of $0.7 \%$ and $6.2 \%$ respectively for the perfilometer and CLSM measurements. In the case of the reference samples, a strong reduction in the fatigue limit was observed, and this is due to the effect of the corner of the square cross section.

Table 2. Summary of the fatigue test results and analysis.

\begin{tabular}{cccccc}
\hline Surface & Equipment & $\begin{array}{c}\mathrm{R}_{\mathrm{z}} \\
(\mu \mathrm{m})\end{array}$ & $\begin{array}{c}\text { Theoretical } \\
\mathrm{K}_{\mathrm{f}}\end{array}$ & $\begin{array}{c}\mathrm{L}_{\mathrm{f}} \\
\text { expected } \\
(\mathrm{MPa})\end{array}$ & $\begin{array}{c}\mathrm{L}_{\mathrm{f}} \\
\text { measured } \\
(\mathrm{MPa})\end{array}$ \\
\hline Reference & Perfilometer & 3.55 & 1.06 & 802 & 725 \\
Reference & CLSM & 2.45 & 1 & 850 & 725 \\
Laser & Perfilometer & 7.55 & 1.35 & 630 & 625 \\
Laser & CLSM & 6.37 & 1.28 & 664 & 625 \\
\hline
\end{tabular}

In summary, the notches from the reference surface finish have a negligible effect; those resulting from laser treatment have a significant effect and the predictable fatigue resistance is consistent with the experimental results. Therefore, the diminished value of the fatigue resistance of treated specimens may be attributed to the notch effect of the laser treatment. As shown throughout the text, neither residual stress nor $\alpha$-case formation influences the fatigue strength in the present study.

\section{Conclusions}

With the process parameters employed, the femtosecond laser provided a regular surface with a bimodal distribution of LIPSS (with around $700 \mathrm{~nm}$ of periodicity) and micro-columns. A surface oxide also resulted from the laser processing. However, the mechanical behavior under cyclic stresses was negatively affected, with a reduction in the fatigue resistance being observed, and must be considered in the design of a load bearing implant. As there was a negligible difference in the residual stresses among modified and non-modified surfaces, the deleterious effect on the fatigue response was ascribed to the increased roughness of the laser treated region, where crack nucleation always occurred after the surface modification.

\section{Acknowledgements}

The authors acknowledge the Brazilian Funding Authority for Studies and Projects (FINEP - process n. 01.08.0610.00) and The São Paulo Research Foundation (FAPESP - process n. 2016/12995-5) for the financial support.

\section{References}

1. Long M, Rack HJ. Titanium alloys in total joint replacement - a materials science perspective. Biomaterials. 1998;19(18):16211639 .

2. Ryan G, Pandit A, Apatsidis DP. Fabrication methods of porous metals for use in orthopaedic applications. Biomaterials. 2006;27(13):2651-2670.

3. Sartoretto SC, Alves AT, Resende RF, Calasans-Maia J, Granjeiro JM, Calasans-Maia MD. Early osseointegration driven by the surface chemistry and wettability of dental implants. Journal of Applied Oral Science. 2015;23(3):279-287.

4. Oliveira DP, Palmieri A, Carinci F, Bolfarini C. Gene expression of human osteoblasts cells on chemically treated surfaces of Ti-6Al-4V-ELI. Materials Science and Engineering: $C$. 2015;51:248-255.

5. Souza MR, Reyes KM, Oliveira NTC, Kuromoto NK, Marino CEB. Bioactivity of self-organized $\mathrm{TiO} 2$ nanotubes used as surface treatment on Ti biomaterials. Materials Research Express. 2016;3(3):035401.

6. Apachitei I, Lonyuk B, Fratila-Apachitei LE, Zhou J, Duszczyk J. Fatigue response of porous coated titanium biomedical alloys. Scripta Materialia. 2009;61(2):113-116.

7. Leinenbach C, Eifler D. Fatigue and cyclic deformation behaviour of surface-modified titanium alloys in simulated physiological media. Biomaterials. 2006;27(8):1200-1208.

8. Campanelli LC, Bortolan CC, da Silva PSCP, Bolfarini C, Oliveira NTC. Effect of an amorphous titania nanotubes coating on the fatigue and corrosion behaviors of the biomedical Ti-6Al-4V and Ti-6Al-7Nb alloys. Journal of the Mechanical Behavior of Biomedical Materials. 2017;65:542-551.

9. Campanelli LC, Oliveira NTC, da Silva PSCP, Bolfarini C, Palmieri A, Cura F, et al. Fatigue resistance, electrochemical corrosion and biological response of Ti-15Mo with surface modified by amorphous $\mathrm{TiO} 2$ nanotubes layer. Journal of Biomedical Materials Research: B. 2019;107(1):86-96.

10. Salou L, Hoornaert A, Louarn G, Layrolle P. Enhanced osseointegration of titanium implants with nanostructured surfaces: an experimental study in rabbits. Acta Biomaterialia. 2015;11:494-502.

11. Oliveira V, Ausset S, Vilar R. Surface micro/nanostructuring of titanium under stationary and non-stationary femtosecond LASER irradiation. Applied Surface Science. 2009;255(17):7556-7560.

12. Oliveira V, Cunha A, Vilar R. Multi-scaled femtosecond laser structuring of stationary titanium surfaces. Journal of Optoelectronic and Advanced Materials. 2010;12(3):654-658.

13. Lee BEJ, Exir H, Weck A, Grandfield K. Characterization and evaluation of femtosecond laser-induced sub-micron periodic structures generated on titanium to improve osseointegration of implants. Applied Surface Science. 2018;441:1034-1042.

14. Macherauch E, Müller P. Das $\sin ^{2}(\Psi)$-Verfahren der röntgenographischen Spannungsmessung. Zeitschrift für Angewandte Physik. 1961;13:305-312. 
15. Cunha A, Serro AP, Oliveira V, Almeida A, Vilar R, Durrieu MC. Wetting behaviour of femtosecond laser textured Ti-6Al4V surfaces. Applied Surface Science. 2013;265:688-696.

16. Wang G, Li J, Lv K, Zhang W, Ding X, Yang G, et al. Surface thermal oxidation on titanium implants to enhance osteogenic activity and in vivo osseointegration. Scientific Reports. 2016;6:31769.

17. Saha RL, Nandy TK, Misra RDK, Jacob KT. Evaluation of the reactivity of titanium with mould materials during casting. Bulletin of Material Science. 1989;12(5):481-493.

18. Sefer B, Roa JJ, Mateo A, Pederson R, Antti ML. Evaluation of the Bulk and Alpha-Case Layer Properties in Ti-6Al-4V at Micro-And Nano-Metric Length Scale. In: Proceedings of the $13^{\text {th }}$ World Conference on Titanium; 2016 Aug 16-20; San Diego, CA, USA. p. 1619-1624.

19. Sung SY, Han BS, Kim YJ. Formation of Alpha Case Mechanism on Titanium Investment Cast Parts. In: Nurul Amin AKM, ed.
Titanium Alloys - Towards Achieving Enhanced Properties for Diversified Applications. London: InTechOpen; 2012. p. 29-42.

20. Lütjering G, Williams JC. Titanium. $2^{\text {nd }}$ ed. New York: SpringerVerlag; 2007.

21. Keanini RG, Watkins GK, Okabe T, Koike M. Theoretical Study of Alpha Case Formation during Titanium Casting. Metallurgical and Materials Transactions B. 2007;38(4):729-732.

22. da Silva PSCP, Campanelli LC, Escobar Claros CA, Ferreira T, Oliveira DP, Bolfarini C. Prediction of the surface finishing roughness effect on the fatigue resistance of Ti-6Al-4V ELI for implants applications. International Journal of Fatigue. 2017;103:258-263.

23. Escobar Claros CA, Oliveira DP, Campanelli LC, da Silva PSCP, Bolfarini C. Fatigue behavior of Ti-6Al-4V alloy in saline solution with the surface modified at a micro- and nanoscale by chemical treatment. Materials Science and Engineering: $C$. 2016;67:425-432. 